\title{
Toxicidade aguda em nível celular de aromatizantes de Biscoito e Tutti-frutti em associação
}

\section{Acute toxicity at the cellular level of flavoring Biscuit and Tutti-frutti in association}

Toxicidad aguda en el nivel celular de aromatizante Galleta y Tutti-frutti en asociación

Ila Monize Sousa Sales ${ }^{1}$ Fabelina Karollyne Silva dos Santos ${ }^{2}$ João Marcelo de Castro e Sousa ${ }^{3}$ Ana Paula Peron ${ }^{4}$

${ }^{1}$ Bolsista de Iniciação Científica do CNPq. Acadêmica do Curso de Curso de Ciências Biológicas, Campus Senador Helvídio Nunes de Barros (CSHNB), da Universidade Federal do Piauí (UFPI).

E-mail: ila_monize@hotmail.com

${ }^{2}$ Bolsista de Iniciação Científica do CNPq. Acadêmica do Curso de Curso de Ciências Biológicas, Campus Senador Helvídio Nunes de Barros (CSHNB), da UFPI. E-mail: f.karolss@hotmail.com

${ }^{3}$ Biólogo. Mestre em Ciências Biológicas. Doutor em Ecologia. Docente do Curso de Curso de Ciências Biológicas, Campus Senador Helvídio Nunes de Barros (CSHNB), da UFPI. E-mail: j.marcelobiologo@hotmail.com

${ }^{4}$ Bióloga. Mestre e Doutora em Genética e Melhoramento. Docente do Curso de Curso de Ciências Biológicas, Campus Senador Helvídio Nunes de Barros (CSHNB), e do Curso de Pós-graduação em Genética

e Melhoramento, Campus Ministro Petrônio Portella (CMPP), da Universidade Federal do Piauí (UFPI). E-mail: anapaulaperon@ufpi.edu.br 
Resumo: Objetivou-se no presente estudo avaliar a toxicidade em nível celular de aromatizantes alimentares de Biscoito e Tutti-frutti, nas doses 0,3; 0,6 e 1,3 mL, combinados entre si, em que para a dose de um aditivo associou-se uma dose diferente do outro aditivo de aroma e sabor em estudo. Para a análise das associações de aromatizantes utilizaram-se as células meristemáticas de raízes de Allium cepa. Após os tratamentos, as raízes foram fixadas, hidrolisadas, coradas e analisadas em microscópio óptico. Os resultados obtidos foram avaliados pelo teste estatístico Qui-quadrado, a 5\%. Com base nos resultados, verificou-se que todas as associações causaram efeito antiproliferativo às células do tecido analisado, mostrando, nas condições de análises estabelecidas, efeito citotóxico. Ainda, os tratamentos induziram número expressivo de alterações de fuso mitótico, como metáfases com perda de cromossomos, metáfases poliploides, pontes anafásicas e telofásicas e micronúcleos, caracterizando tais associações como genotóxicas. Esses resultados sugerem que esses aditivos em combinação têm habilidade em causar toxicidade em nível celular. Assim, outros testes, tais como aqueles com roedores e em culturas de células, devem ser realizados, com premência, a fim de definir melhor a toxicidade de tais microingredientes, de modo a assegurar adequadamente a segurança da população que faz uso deles.

Palavras-chave: aditivos de aroma e sabor; toxicidade, ciclo celular, alterações celulares; tecido meristemático.

\begin{abstract}
The objective in the present study to evaluate the toxicity at the cellular level of food flavorings Biscuit and Tutti-frutti, at doses 0.3; 0.6 and $1.3 \mathrm{ml}$, combined, where for the dose of an additive joined to a different dose of another flavor and taste additive under study. For the analysis of flavor associations was used meristematic cells of Allium cepa roots. After the treatments, the roots were fixed, hydrolysed, stained and examined under an optical microscope. The results were evaluated by statistical test Chi-square, $5 \%$. Based on the results it was found that all associations antiproliferative effect caused cells from tissue analyzed, being in the set analysis conditions, such as cytotoxic. Still, the treatments induced significant number of mitotic spindle changes, as metaphases with loss of chromosomes, metaphase polyploid, anafásicas bridges and telofásicas, and micronuclei, which demonstrated significant genotoxic potential. These results suggest that this additive has the potential to lead toxicity in cell level. Thus, other tests, such as those using rodents and cell cultures should be performed with urgency to better assess toxicity of such micro ingredients.
\end{abstract}

Key words: aroma and flavor addtives; toxicity; cell cycle; cellular changes; meristematic tissues.

Resumen: El objetivo en el presente estudio para evaluar la toxicidad a nivel celular de los aromas alimentarios Galleta y Tutti-frutti, a dosis de 0,3; 0,6 y 1,3 ml, combinado, donde para la dosis de un aditivo unido a una dosis diferente de otro sabor y el gusto aditivo en estudio. Para el análisis de las asociaciones de sabor se utilizó células meristemáticas de raíces de Allium серa. Después de los tratamientos, las raíces se fijaron, se hidrolizan, se tiñen y se examinan bajo un microscopio óptico. Los resultados se evaluaron mediante la prueba estadística de Chi-cuadrado, 5\%. Basándose en los resultados se encontró que todas las asociaciones antiproliferativa efecto causado células de tejido analizado, siendo en las condiciones de análisis de conjunto, tales como citotóxica. Aún así, los tratamientos indujeron número significativo de cambios de huso mitótico, como metafases con la pérdida de cromosomas, poliploide metafase, anafásicas puentes y telofásicas y micronúcleos, lo que demuestra el potencial genotóxico significativo. Por lo tanto, las otras pruebas, tales como los que utilizan los roedores y los cultivos celulares deben llevarse a cabo con urgencia, para una mejor evaluación de la toxicidad de dichos ingredientes micro para garantizar la seguridad de las personas que hacen uso de ellos

Palabras clave: arma y sabor aditivos; toxicidade; ciclo celular; tejido meristemático. 


\section{INTRODUÇÃO}

A globalização e o desenvolvimento de novas tecnologias causaram significativas modificações no hábito alimentar da população, a qual, nas últimas décadas, incorporou ao seu cotidiano alimentos ricos em aditivos ou microingredientes alimentares. Dentre esses compostos, estão os aditivos aromatizantes sintéticos, ingredientes de grande relevância para a indústria alimentícia em razão de conferirem propriedades sensoriais de aroma e sabor aos mais variados tipos de alimentos industrializados. Tais microingredientes possuem formulação complexa, constituída por uma variedade de compostos químicos, como aqueles de ação diluente, conservante e umectante.

Em âmbito mundial, os aromatizantes são normatizados e autorizados para uso pelos órgãos de segurança alimentar Food and Agriculture Organization (FAO) e Flavour and Extract Manufactuer Association (FEMA), e nacionalmente pela Agência Nacional de Vigilância Sanitária (ANVISA) por meio da Resolução RDC n. 2 de 15 de janeiro de 2007 (BRASIL, 2007). Entretanto esses órgãos reguladores não possuem definidos o índice de Ingestão Diária Aceitável (IDA) e as doses limites toleráveis desses microingredientes para as diversas classes de alimentos industrializados disponibilizadas comercialmente. Tal condição é devida à falta de estudos de avaliações toxicológicas para essas substâncias de aroma e sabor.

Em atenção a essa carência de informações, as próprias agências reguladores, FEMA e ANVISA, em seus documentos técnicos, classificam como prioritária a realização de pesquisas que avaliem os potenciais citotóxicos e genotóxicos dos microingredientes de aroma e sabor, por meio de diferentes bioensaios (BRASIL, 2007), e sugerem as células meristemáticas de raízes de Allium cepa $\mathrm{L}$. (cebola) como um importante sistemas teste para o screnning inicial da toxicidade aguda em nível celular de aditivos alimentares em geral. 
No entanto, apesar da escassez de estudos sobre a ação dos aditivos de aroma e sabor em nível celular, encontra-se na literatura, também em número reduzido, avaliações de toxicidade de alguns componentes químicos que fazem parte da composição básica dos aromatizantes alimentares em geral, e que demonstraram citotoxicidade e genotoxicidade significativas aos bioensaios aos quais foram testados, corroborando, como será mostrado adiante, os resultados obtidos aqui com aromatizantes alimentares. Dentre essas pesquisas, estão as de Tükoğlu (2007), Whittaker et al. (2008), Demir, Kocaoglu e Kaya (2010) e Zequin et al. (2011).

Portanto, com base no contexto abordado, teve-se por objetivo avaliar a citotoxicidade e a genotoxidade de aromatizantes alimentares sintéticos artificiais de Biscoito e Tutti-frutti combinados entre si, uma vez que esses dois aditivos são amplamente encontrados em associação em biscoitos recheados, bolachas wafer, cakes, cookies, brownies, entre outros alimentos industrializados.

\section{MATERIAIS E MÉTODOS}

Os aditivos de aroma e sabor de Biscoito e Tutti-frutti foram obtidos de uma empresa localizada na cidade de Recife, Estado de Pernambuco, Brasil, especializada na fabricação e comercialização nacional e internacional de aditivos alimentares sintéticos em geral.

No rótulo dos dois aromatizantes, sugeria-se a utilização de $3 \mathrm{ml}$ de aditivo para $1,0 \mathrm{Kg}$ de massa. Os bulbos de $A$. cepa selecionados para a avaliação de toxicidade tinham, em média, 200g. Assim, de forma proporcional ao recomendado nos frascos dos dois microingredientes, definiu-se inicialmente para análise a dose $0,6 \mathrm{ml} \mathrm{e,} \mathrm{a}$ partir dela, estabeleceram-se duas outras, 0,3 e 1,2 ml. Avaliaramse os tais aditivos associados entre si, nos quais, para cada dose do aromatizante de Biscoito (BIS), combinou-se uma dose diferente do 
aditivo de Tutti-Frutti (TF). Desse modo, os tratamentos em associação analisados no presente estudo foram: BIS 0,3 mL / TF 0,6 mL; BIS 0,6 mL / TF 0,3 mL; BIS 1,2 mL / TF 0,3 mL; BIS 0,3 mL / TF 1,2 mL; BIS 1,2 $\mathrm{mL} / \mathrm{TF}$ 0,6 mL; BIS 0,6 mL / TF 1,2 mL.

Para a realização desse bioensaio, bulbos de cebola foram postos em frascos aerados com água destilada, à temperatura ambiente $( \pm$ $27^{\circ} \mathrm{C}$ ), aerados constantemente, até a obtenção de raízes de $2,0 \mathrm{~cm}$ de comprimento. Para a análise de todo o tratamento utilizaram-se cinco bulbos de cebola. Antes de colocar os bulbos em contato com os seus respectivos tratamentos, algumas raízes foram coletadas e fixadas para servirem de controle do próprio bulbo. Em seguida, as raízes restantes foram postas em suas respectivas soluções por 24 horas, procedimento denominado de tempo de exposição 24 horas. Após esse tempo, foram retiradas algumas raízes e fixadas.

Feito tal procedimento, as raízes restantes de cada cebola foram devolvidas aos seus respectivos tratamentos onde permaneceram por mais 24 horas, o que se denominou de tempo de exposição 48 horas. Após esse período, raízes novamente foram coletadas e fixadas. A fixação das raízes se deu em Carnoy 3:1 (etanol: ácido acético) por 24 horas. Em cada coleta, retiram-se, em média, três raízes por bulbo. Portanto todo o tratamento foi constituído de três grupos de análise, o Controle, o Tempo de Exposição 24 horas e o Tempo de Exposição 48 horas e, para cada grupo, analisou-se um total de 5.000 células, ou seja, mil células por bulbo.

As lâminas, em média 03 por bulbo, foram preparadas seguindo o protocolo proposto por Guerra e Souza (2002), e analisadas em microscópio óptico em objetiva de 40x, onde se observou células em interfase, prófase, metáfase, anáfase e telófase para a determinação do índice de divisão celular ou índice mitótico. Avaliou-se também a ação dos tratamentos com base na frequência de alterações celulares, como as alterações ocasionadas pelo não alinhamento correto 
dos cromossomos na placa equatorial, as decorrentes do atraso de cromossomos durante a movimentação ocasionada pelas fibras do fuso mitótico, as oriundas de quebras cromossômicas com a formação de fragmentos acêntricos e/ou cromossomos em atraso que permaneceram à deriva na célula ao final da divisão celular, entre outros distúrbios celulares. Os resultados obtidos foram analisados pelo teste estatístico Qui-quadrado $\left(\chi^{2}\right)$, a $5 \%$, por meio do programa BioEstat 4.0 (AYRES et al., 2005).

\section{RESULTADOS E DISCUSSÃO}

É importante esclarecer que compostos citotóxicos e genotóxicos têm o potencial de alterar mecanismos celulares vitais, como a duplicação e a transcrição gênica, bem como, promoverem alterações de fuso mitótico. Tais alterações podem comprometer significativamente a divisão celular do tecido ou órgão afetado e desencadear e/ou potencializar processos cancerosos (ZILIFDAR et al., 2014). De acordo com Zaineddin et al. (2012) Sales et al. (2017), o desenvolvimento dos tipos mais comuns de câncer resulta da interação entre fatores endógenos e ambientais, sendo o mais notável deles a dieta alimentar, particularmente quando constituída de alimentos industrializados em demasia.

Conforme descrito na Tabela 1, as combinações de doses de Biscoito e Tutti-frutti, BIS 0,3 mL/TF 0,6 mL; BIS 0,3 mL / TF 1,2 mL; BIS 1,2 mL / TF 0,6 mL e BIS 0,6 / TF 1,2 mL, causaram redução expressiva da divisão celular nos tecidos meristemáticos de raízes imediatamente no menor tempo de análise avaliado. Em $A$. cepa, esse resultado caracteriza tais associações como citotóxicas. 
Tabela 1 - Número de células observadas em cada fase do ciclo celular presentes em tecido meristemático de raízes de Allium cepa tratados com água e com os aromatizantes alimentares sintéticos artificiais de Biscoito e Tutti-frutti, nas doses de 0,3; 0,6 e 1,2 ml, associados entre si, e avaliado nos tempos de exposição 24 e 48 horas

\begin{tabular}{ccccccccc}
\hline \multicolumn{5}{c}{ AROMATIZANTE DE BISCOITO / AROMATIZANTE DE TUTTI-FRUTTI } \\
\hline Doses associadas (mI) & TE & TCII & $\mathbf{P}$ & $\mathbf{M}$ & $\mathbf{A}$ & $\mathbf{T}$ & TCD & IM (\%) \\
\hline \multirow{3}{*}{ BIS 0,3 / TF 0,6 } & CO & 3867 & 776 & 198 & 190 & 209 & 1373 & $27,5^{\mathrm{a}}$ \\
& $24 \mathrm{~h}$ & 4247 & 468 & 177 & 77 & 31 & 753 & $15,1^{\mathrm{b}}$ \\
& $48 \mathrm{~h}$ & 4301 & 471 & 124 & 81 & 23 & 699 & $14,0^{\mathrm{b}}$ \\
\hline \multirow{3}{*}{ BIS 0,6 / TF 0,3 } & CO & 3778 & 714 & 192 & 158 & 156 & 1222 & $24,4^{\mathrm{a}}$ \\
& $24 \mathrm{~h}$ & 4531 & 161 & 145 & 79 & 84 & 469 & $9,4^{\mathrm{b}}$ \\
& $48 \mathrm{~h}$ & 4551 & 137 & 123 & 91 & 98 & 449 & $9,0^{\mathrm{b}}$ \\
\hline \multirow{3}{*}{ BIS 1,2 / TF 0,3 } & CO & 3630 & 779 & 245 & 172 & 174 & 1370 & $27,4^{\mathrm{a}}$ \\
& $24 \mathrm{~h}$ & 4423 & 333 & 106 & 66 & 72 & 577 & $11,5^{\mathrm{b}}$ \\
& $48 \mathrm{~h}$ & 4331 & 332 & 162 & 83 & 92 & 669 & $13,4^{\mathrm{b}}$ \\
\hline \multirow{3}{*}{ BIS 0,3 / TF 1,2 } & CO & 4054 & 432 & 223 & 187 & 104 & 946 & $18,9^{\mathrm{a}}$ \\
& $24 \mathrm{~h}$ & 4818 & 92 & 41 & 32 & 17 & 182 & $3,6^{\mathrm{b}}$ \\
& $48 \mathrm{~h}$ & 4826 & 84 & 37 & 39 & 14 & 174 & $3,5^{\mathrm{b}}$ \\
\hline \multirow{3}{*}{ BIS 1,2 / TF 0,6 } & CO & 4115 & 542 & 136 & 93 & 114 & 885 & $17,7^{\mathrm{a}}$ \\
& $24 \mathrm{~h}$ & 4580 & 290 & 61 & 47 & 22 & 420 & $8,4^{\mathrm{b}}$ \\
& $48 \mathrm{~h}$ & 4575 & 293 & 61 & 52 & 19 & 425 & $8,7^{\mathrm{b}}$ \\
\hline \multirow{3}{*}{ BIS 0,6 / TF 1,2 } & CO & 4114 & 479 & 134 & 170 & 103 & 886 & $17,7^{\mathrm{a}}$ \\
& $24 \mathrm{~h}$ & 4768 & 93 & 76 & 47 & 16 & 232 & $4,6^{\mathrm{b}}$ \\
& $48 \mathrm{~h}$ & 4785 & 84 & 84 & 28 & 19 & 215 & $4,3^{\mathrm{b}}$ \\
\hline
\end{tabular}

BIS: Aromatizante de Biscoito; TF: Aromatizante de Tutti-Frutti; TE: Tempo de exposição; TCII: Total de Células em Interfase e Indiferenciadas; P: Profase; M: Metáfase; A: Anáfase; T: Telófase; TCD: Total de Células em Divisão; IM: Índice Mitótico. Para cada tratamento, valores de IM seguidos da mesma letra não diferem significativamente ao nível de $5 \%$ pelo teste $\chi^{2}$.

De acordo com Gomes et al. (2013) e Santana et al. (2016), a inibição da divisão celular é decorrente de morte celular devido a distúrbios ocorridos, como por ação tóxica de substâncias ou compostos químicos, na cinética de divisão celular ou a cromossomos essenciais as células. Tais eventos, segundo Nunes et al. (2016), causam redução significativa da reposição celular e alteram a síntese proteica do tecido ou órgão onde ocorrem. 
Com base nos resultados da Tabela 2, verifica-se que todas as associações de aromatizantes avaliadas causaram número expressivo de alterações de fuso mitótico às células do organismo de prova utilizado. As variações observadas foram metáfases poliploides, metáfases com perda de cromossomos, metáfases colchicínicas, pontes anafásicas, pontes telofásicas, micronúcleos e células binucleadas (Figura 1). Em razão desse resultado, as associações de Biscoito e Tutti-frutti, nessas condições de estudo, demonstraram relevante atividade genotóxica.

Tabela 2 - Número e tipos de alterações celulares observadas em células de tecido meristemático de raízes de Allium cepa tratados com água e com os aromatizantes alimentares sintéticos artificiais de Biscoito e Tutti-frutti, nas doses de 0,3; 0,6 e 1,2 mL, associados entre si, e avaliados nos tempos de exposição 24 e 48 horas.

\begin{tabular}{cccccccc}
\hline Doses associadas (mL) & TE & MP & MPC & PAT & MCN & CB & TAC \\
\hline \multirow{3}{*}{ BIS 0,3 / TF 0,6 } & CO & 00 & 00 & 00 & 00 & 01 & 01 \\
& $24 h$ & 17 & 24 & 31 & 32 & 09 & $113^{b}$ \\
& $48 \mathrm{~h}$ & 13 & 39 & 37 & 31 & 07 & $127^{\mathrm{b}}$ \\
\hline \multirow{3}{*}{ BIS 0,6 / TF 0,3 } & CO & 01 & 00 & 00 & 00 & 00 & $01^{\mathrm{a}}$ \\
& $24 \mathrm{~h}$ & 11 & 17 & 19 & 34 & 04 & $85^{\mathrm{b}}$ \\
& $48 \mathrm{~h}$ & 09 & 19 & 17 & 39 & 07 & $91^{\mathrm{b}}$ \\
\hline \multirow{3}{*}{ BIS 1,2 / TF 0,3 } & CO & 00 & 00 & 00 & 01 & 00 & $01^{\mathrm{a}}$ \\
& $24 \mathrm{~h}$ & 19 & 21 & 24 & 39 & 03 & $106^{\mathrm{b}}$ \\
& $48 \mathrm{~h}$ & 21 & 17 & 27 & 31 & 04 & $100^{\mathrm{b}}$ \\
\hline \multirow{3}{*}{ BIS 0,3 / TF 1,2 } & CO & 00 & 00 & 01 & 00 & 00 & $01^{\mathrm{a}}$ \\
& $24 \mathrm{~h}$ & 03 & 19 & 21 & 29 & 01 & $73^{\mathrm{b}}$ \\
& $48 \mathrm{~h}$ & 07 & 23 & 17 & 29 & 04 & $80^{\mathrm{b}}$ \\
\hline \multirow{3}{*}{ BIS 1,2 / TF 0,6 } & CO & 00 & 01 & 00 & 00 & 00 & $01^{\mathrm{a}}$ \\
& $24 \mathrm{~h}$ & 13 & 11 & 13 & 34 & 09 & $80^{\mathrm{b}}$ \\
& $48 \mathrm{~h}$ & 13 & 17 & 19 & 32 & 10 & $91^{\mathrm{b}}$ \\
\hline \multirow{2}{*}{ BIS 0,6 / TF 1,2 } & CO & 00 & 00 & 01 & 00 & 00 & $01^{\mathrm{a}}$ \\
& $24 \mathrm{~h}$ & 21 & 17 & 21 & 32 & 11 & $102^{\mathrm{b}}$ \\
& $48 \mathrm{~h}$ & 27 & 19 & 19 & 29 & 09 & $103^{\mathrm{b}}$ \\
\hline
\end{tabular}

BIS - Aromatizante de Biscoito; TF - Aromatizante de Tutti-frutti; TE - Tempo de Exposição; MP: Metáfase Poliplóide; MPC - Metáfase com Perda de Cromossomo; PAT: Ponte Anafásica e Telofásica; MCN - Micronucleo; CB - Célula Binucleada; TCA: Total de Células com Alterações. Valores de IM seguidos da mesma letra dentro de um mesmo tratamento não diferem significativamente entre si ao nível de $5 \%$ pelo teste $\chi^{2}$. 


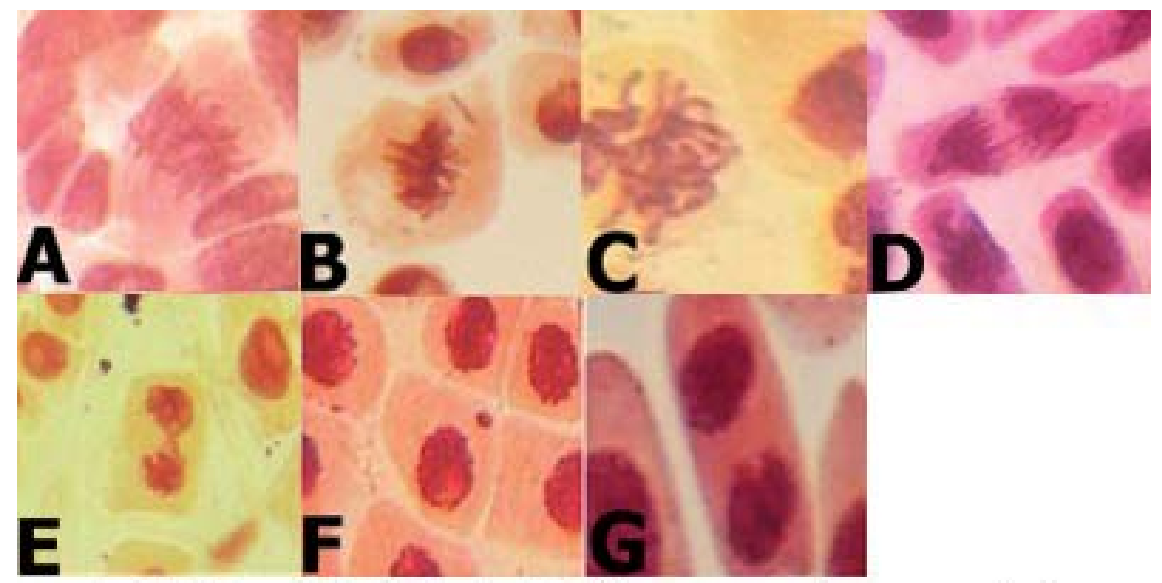

A - Metáfase Poliplóide. B - Metáfase com perda cromossômica.

C. Metáfase Colchícinica. D - Ponte Anafásica. E - Ponte Telofásica. F - Micronúcleo. G - Célula Binucleada

Figura 1 - Alterações de fuso mitótico decorrentes do tratamento de tecido meristemático de raiz de Allium cepa expostos aos aromatizantes alimentares sintéticos artificiais de Biscoito e Tuttifrutti, nas doses de 0,3; 0,6 e 1,2 ml, associados entre si, e avaliado nos tempos de exposição 24 e 48 horas

Aissa et al. (2012) e Zilifdar et al. (2014) relatam que metáfases com alinhamento incorreto de cromossomos na placa equatorial, as denominadas metáfases colchicínicas, e as metáfases com perda de cromossomo podem desencadear a formação de células binucleadas e também, após sucessivas divisões celulares, a formação de metáfases poliploides, do mesmo modo que outras alterações celulares, tal como as pontes anafásicas e telofásicas darão origem aos micronúcleos ou a células micronucleadas. Essas variações de fuso mitótico, quando recorrentes, ocasionam células com números cromossômicos distintos. Considerando que o princípio do ciclo celular é a formação de células idênticas, a produção de células com alteração na estrutura e/ ou no número cromossômico tornam o funcionamento celular inviável 
e tendem a ser eliminadas de tecidos com desempenho normal. Por conseguinte, as variações significativas de fuso mitótico observadas neste estudo corroboram aos resultados de redução da divisão celular descritos na Tabela 1.

Ainda, Zaineddin et al. (2012) e Queiroz et al. (2013) ressaltam que micronúcleos, quando em presença expressiva, promovem citotoxicidade sistêmica por causarem elevadas taxas de mutação e, consequentemente, instabilidade genética nas células. É importante mencionar que, de acordo com esses pesquisadores, apesar da toxicidade genética não ser medida de carcinogenicidade, ela está frequentemente associada ao aparecimento de câncer, visto que há uma correlação positiva entre o aumento da frequência de micronúcleos e o aparecimento de tumores em mamíferos. Assim, os resultados obtidos aqui com A. cepa indicam a urgente necessidade de se avaliar as associações de Biscoito e Tutti-frutti aqui estudadas em sistemas testes com animais e em cultura de células.

Não se encontrou na literatura nem nos rótulos dos aromatizantes a composição química referente aos aditivos de Biscoito e Tutti-frutti. No entanto, na literatura científica, foram encontrados trabalhos que demonstram toxicidade em nível celular de constituintes químicos com ações diluente e conservante presentes, segundo a Resolução RDC n. 2 de 15 de janeiro de 2007 (BRASIL, 2007), na formulação básica dos aditivos de aroma e sabor, e que corroboram os dados obtidos para os três aromatizantes avaliados no presente estudo. Entre esses compostos, está o álcool benzoico, responsável por manter a uniformidade e facilitar a incorporação e dispersão dos aromas nos produtos alimentícios. Em análise à ação em nível celular desse diluente, Demir, Kocaoglu e Kaya (2010) verificaram que esse álcool promoveu danos significativos ao fuso mitótico, e, consequentemente, a divisão celular de células de sangue periférico humano. 
Outro diluente encontrado na formulação dos aromatizantes é o diacetil (2,3-butadiona). Whittaker et al. (2008) citam que esse composto em ensaio de mutação gênica em linfoma de ratos causou danos significativos ao loci do cromossomo 11 dessas células, causando perda de expressão dos genes para enzima timidina-quinase. Além disso, More, Raza e Vince (2012) verificaram que o diluente diacetil teve o potencial de substituir bases de timina por guaninas em regiões de eucromatina e ocasionar o rompimento de pontes de hidrogênio e de dissulfeto em estrutura terciária de enzimas envolvidas no processo de divisão celular.

Já entre os constituintes químicos responsáveis em retardar a ação de microrganismos, enzimas e agentes físicos nas soluções de aroma e sabor, estão o benzoato de potássio, benzoato de sódio e nitrato de potásio (BRASIL, 1999), agentes conservantes que, segundo Zequin et al. (2011), foram citotóxicos e genotóxicos a células normais de sangue periférico humano. Na composição dos aromatizantes alimentares, também são encontrados os compostos conservantes ácido bórico, ácido cítrico, citrato de potássio e citrato de sódio (BRASIL, 1999) que, de acordo Tükoğlu (2007), acarretaram redução significativa ao índice de divisão celular de células de meristemas de raízes de $A$. cepa, mostrando-se citotóxicos.

Atualmente, na formulação dos aromatizantes alimentares, a única classe de compostos que possui restrição de uso normatizada pelos órgãos de segurança alimentar é a de solventes de extração, em que o ácido agárico, aloina, beta-azorona, berberina, cumarina, ácido cianídrico, hipericina, pulegona, quassina, safrol e isosafrol, santonina e tuyona alfa e beta possuem limites máximos toleráveis discriminados em documento (BRASIL, 1999; 2007). Porém, segundo Moura et al. (2016) e Konishi, Hayashi e Fukushima (2014), na composição dos aromatizantes em geral, 11 são as classes de compostos químicos encontradas, nas quais cada uma é formada, em média, por 
20 compostos químicos, os quais não foram avaliados quanto aos seus potenciais citotóxicos, genotóxicos e mutagênicos.

Sobre a toxicidade dos aromatizantes em geral, a ANVISA, apesar de não citar quais estudos, concentrações e compostos, nem quais aromatizantes determinaram tal conclusão, declaram que doses elevadas de tais aditivos sintéticos provocam ações irritantes e narcóticas ao organismo, podendo ocasionar toxicidade ao trato digestório quando utilizadas cronicamente e de maneira indiscriminada (BRASIL, 1999; 2007). Entretanto, outros estudos, como o de Polônio e Peres (2009), declaram que a utilização de aromatizantes alimentares em baixas doses não promove risco à saúde humana, porém, quando são elevadas, podem provocar ações irritantes, narcóticas e toxicidade celular crônica em longo prazo, sempre que empregados em doses superiores às recomendadas. Contudo essas pesquisas não especificam quais doses ou concentrações de aromatizantes são consideradas elevadas ou baixas.

\section{CONSIDERAÇÕES FINAIS}

Embora a utilização dos aromatizantes alimentares seja permitida pela EFSA, FEMA e ANVISA, há urgente necessidade de esclarecimentos, por meio de estudos mais detalhados, a médio e longo prazo, em diferentes sistemas testes, dosagens e tempo de exposição, quanto à toxicidade dessas substâncias.

Os resultados obtidos aqui, mesmo que preliminares, aliados aos resultados de avaliação da toxicidade em nível celular de compostos presentes na formulação dos aromatizantes alimentares já realizadas, indicam a necessidade em definir, como por cromatografia de alta performance, a composição química dos aromatizantes em geral, para assim se determinar com propriedade a toxicidade desses aditivos e garantir a segurança daqueles que os consomem. 
Toxicidade aguda em nível celular de aromatizantes de Biscoito e Tutti-frutti em associação

\section{REFERÊNCIAS}

AISSA, A. F.; BIANCHI, M. L. P.; RIBEIRO, J. C.; HERNANDES, L. C.; FARIA, A. F.; MERCADANTE, A. Z.; ANTUNES, L. M. G. Comparative study of $\beta$-carotene and microencapsulated $\beta$-carotene: evaluation of their genotoxic and antigenotoxic effects. Food Chemical and Toxicology, v. 50, n. 5, p. 14181424, 2012. DOI:10.1016/j.fct.2012.02.030

AYRES M.; AYRES J. R. M.; AYRES D. L.; SANTOS A. S. BioEstat 5.0: aplicações estatísticas nas áreas das Ciências Biológicas e Médicas. Belém: MCT/IDSM/ CNPq, 2007. 340p.

BRASIL. Agência Nacional de Vigilância Sanitária. Resolução RDC n. 2, de 15 de janeiro de 2007. Aprova o Regulamento Técnico sobre as atribuições de aditivos em geral e seus limites máximos para a categoria e alimentos.

BRASIL. Agência Nacional de Vigilância Sanitária. Resolução-RDC n. 104, de 14 de maio de 1999. Aprova o Regulamento Técnico sobre aspectos gerais de Aditivos Aromatizantes/Aroma.

DEMIR, E.; KOCAOGLU, S.; KAYA, R. Assessment genotoxic effects of benzyl derivatives by comet assay. Food Chemical and Toxicology, v. 48, n. 5, p. 1239-1242, 2010. DOI:10.1016/j.fct.2010.02.016

GOMES, K. M. S.; OLIVEIRA, M. V. G. A.; CARVALHO, F. R. S.; MENEZES, C. C.; PERON, A. P. Citotoxicity of food dyes sunset yellow (E-110), bordeax red (E123), and tatrazine yellow (E-102) on Allium cepa L. root meristematic cells. Ciência e Tecnologia de Alimentos, v. 33, n. 1, p. 218-223, 2013. DOI:10.1590/ S0101-20612013005000012

GUERRA, M.; SOUZA M. J. Como observar os cromossomos: um guia de técnicas em citogenética vegetal, animal e humana. Ribeirão Preto, SP: FUNPEC, 2002. 320 p.

KONISHI, Y.; HAYASHI, S.M.; FUKUSHIMA, S. Regulatory forum opinion piece: supporting the need for international harmonization of safety assessments for food flavoring substance. Toxicologic pathology, v. 42, n. 6, p. 949-953, 2014. DOI: $10.1177 / 0192623313495603$

MORE, S. S.; RAZA, A.; VINCE, R. The butter flavorant, diacetyl, forms a covalent adduct with 2-deoxyguanosine, uncoils DNA, and leads to cell death. Journal of Agricultural and Food Chemistry, v. 60, n. 12, p. 3311-3317, 2012. DOI: 10.1021/jf300180e 
MOURA, A. G.; SANTANA, G. M.; FERREIRA, P. M. P.; SOUSA, J. M. C.; PERON, A. P. Cytotoxicity of Cheese and Cheddar Cheese food flavorings on Allim cepa $L$ root meristems. Brazilian Journal of Biology, v. 76, n. 2, p. 439-443, 2016. DOI: 10.1590/1519-6984.20514

NUNES, R. D. M.; SALES, I. M. S.; SILVA, S. I. O.; SOUSA, J. M. C.; PERON, A. P. Antiproliferative effects and identical and artificial synthetic food additives of aroma and flavor. Brailian Journal of Biology, v. 76, n. 4, 2016. DOI:101590/1514-6984.12115

POLÔNIO, M. L. T.; PERES, F. Food additive intake and health effects: public health challenges in Brazil. Cadernos de Saúde Pública, Rio de Janeiro, v. 25, n. 8, ago. 2009. DOI: 10.1590/S0102-311X2009000800002

QUEIROZ, F. M. D.; MATIAS, K. W. D. O.; CUNHA, M. M. F. D.; SCHWARZ, A. Evaluation of (anti) genotoxic ctivities of Phyllanthus niruri L. in rat bone marrow using the micronucleus test. Brazilian Journal of Pharmaceutical Science, São Paulo, v. 49, n. 1, p. 135-148, jan./mar. 2013. DOI:10.1590/ S1984-82502013000100015

SALES, I. M. S.; BARBOSA, J. S.; SANTOS, F. K. S.; SILVA, F. C. C.; FERREIRA, P. M. P.; SOUSA, J. M. C.; PERON, A. P. Acute toxicity of grape, plum and orange synthetic food flavourings evaluated in vivo test systems. Food Technology and Biotechnology, v. 55, n. 1, 2017. [in press].

SANTANA, G. M.; DEUS, M. S. M.; SOUSA, J. M. C.; FERREIRA, P. M. P.; FERNANDES, H. B.; PERON, A. P. Antimitotic and antimutagenic action of the Hymenaea stigonocarpa bark on dividing cells. Brazilian Journal of Biology, São Carlos, SP, v. 76, n. 2, p. 520-525, abr./jun. 2016. DOI: 10.1590/1519-6984.23014

TÜRKOĞLU, Ş. Genotoxicity of five food preservatives tested on root tips of Allium cepa L. Mutation Research, v. 626, n. 1, p. 4-14, 2007. DOI:10.1016/j. mrgentox.2006.07.006

WHITTAKER, P.; CLARKE, J. J.; SAN, R. H.; BEGLEY, T. H.; DUNKEL, V. C. Evaluation of the butter flavoring chemical diacetyl and a fluorochemical paper additive for mutagenicity and toxicity using the mammalian cell gene mutation assay in L5178Y mouse lymphoma cells. Food Chemical and Toxicolgy, v. 46, n. 8, p. 2928-2933, 2008. DOI:10.1016/J.FCT.2008.06.001

ZAINEDDIN, A. K.; BUCK, K.; VRIELING, A.; HEINZ, J.; FLESCH-JANYS, D.; LINSEISEN, J.; CHANG-CLAUDE, J. The association between dietary lignans, 
phytoestrogen-rich foods, and fiber intake and postmenopausal breast cancer risk: a German case-control study. Nutrition and Cancer, v. 64, n. 5, p. 652-665, 2012. DOI:10.1080/01635581.2012.683227

ZEQUIN, N.; YÜZBAŞIOĞLU, D.; UNAL, F.; YILMAZ, S.; AKSOY, H. The evaluation of the genotoxicity of two food preservatives: sodium benzoate and potassium benzoate. Food Chemical and Toxicology, v. 49, n. 4, p. 763-769, 2011. DOI:10.1016/j.fct.2010.11.040

ZILIFDAR, F.; ALPES-HAYTA, S.; YILMAZ, S.; KAPLAN-ORZEN, C.; FOTO, E.; AYDOGAN, N. Genotoxic potential and eukaryotic DNA topoisomerase inhibitory effects of some benzoxazine derivative. Medicinal Chemistry Research, v. 23, n. 1, p. 480-86, 2014. DOI:10.1016/j.fct.2012.02.030 
